\title{
Study on Dynamic Import of Model in Virtual Training
}

\author{
Qili $\mathrm{Hu}$ \\ College of Mechanical Engineering, University of Shanghai for Science and Technology \\ 516 Jun Gong Road, Shanghai 200093, China \\ Tel: 86-187-2139-3320 E-mail: huqili03@126.com \\ Jianzhong Lin \\ College of Mechanical Engineering, University of Shanghai for Science and Technology \\ 516 Jun Gong Road, Shanghai 200093, China \\ Baojiang Du \\ College of Mechanical Engineering, University of Shanghai for Science and Technology \\ 516 Jun Gong Road, Shanghai 200093, China \\ Enqi Wu \\ College of Mechanical Engineering, University of Shanghai for Science and Technology \\ 516 Jun Gong Road, Shanghai 200093, China
}

$\begin{array}{lcc}\text { Received: October 13, } 2011 & \text { Accepted: October 25, } 2011 \quad \text { Published: January 1, } 2012 \\ \text { doi:10.5539/mas.v6n1p97 } & \text { URL: http://dx.doi.org/10.5539/mas.v6n1p97 }\end{array}$

\begin{abstract}
Focus on the deficiency of model handling in the virtual training; it puts forward a method of the model dynamic importing. Through the establishment of virtual prototype and definition of model precision, this paper establishes the geometric model and details bases. And according to the corresponding relation between the information of the model and the precision in the post information base, it realizes the importing of the model dynamically. And the necessity and feasibility of the technology is illuminated taking tunnel boring machine (TBM) for example.
\end{abstract}

Keywords: Dynamic Import, Virtual Prototype, Virtual Training, TBM

\section{Introduction}

Virtual training is defined as a kind of virtual environment based on the virtual manufacturing technology and the environment is applied to education and training, the trainees are immersed in a life-like virtual environment for learning and training, greatly improving the efficiency of learning and fun. At present, the virtual training technique has been applied to the substation management, oil and gas gathering and transportation equipment repairing, and other aspects.

Due to the complexity of structure and motion of the large mechanical equipment system, it needs more advanced training methods for improving the efficiency. According to the large amount data of the model and the different work post, this paper studies the dynamic import and dynamic call of the model in the virtual training, and takes the tunnel boring machine (TBM) for example.

At present, the technology of the dynamic import, in the building of virtual scene, has been used more and more widely. Hu Xingen puts forward and realizes an effective method of building the object model in the scene using the dynamic technology by Virtual Reality Markup Language (VRML).Yuan Haibo puts forward an argument building dynamically and visualization of virtual scene and hierarchical processing of operating space based on object-oriented spatial data model.

This paper has realized the way to the import of complex equipment model fast and effectively by Virtual 
prototype building, model optimization and the generation of equipment movement.

\section{Overall Architecture}

This paper has built a model base and defined the movement form and movement logic of the model; it imports the different geometric model dynamically according to the different posts and different model precision, in order to realize fast operation of the virtual training system. Figure 1 is the overall architecture diagram of virtual training system.

\section{Construction of Virtual Prototype}

Virtual prototype is the technology used computer digital model based on integrated product design; it combined the digital models together in the different projects field, in order to simulate the appearance, function and behavior of the real product.

In this paper the virtual prototype is no longer confined in the design stage, it is applied to the presentation and interaction in the training. So the requirements for physical information of the model except the performance and appearance are not high. In order to adapt to the demand of the dynamic import, this paper carries on the construction of the virtual prototype from the kinematic chain and post.

The geometric models construct the virtual prototype as the basic units for virtual training. It pursues the fidelity of model and the interaction in the virtual scene. Virtual prototype has not only consistent appearance and behavior with material object, but there is also the fast speed to meet the real-time display and the function of user interaction.

Therefore, the virtual prototype has been constructed by static geometry models built by the CAD software according to sports chain and the different training posts. According to the different posts and function of the model in the kinematic chain, it is divided into three parts. They are the driving mechanism, the transmission mechanism and actuating mechanism. Virtual training focus on moving parts for demonstration in operation training, the moving parts for operation needed for different posts are different. For example, in the TBM, the operation of screw machine as a training post, its important models can be divided into the driving mechanism, transmission mechanism and actuating mechanism.

Therefore, the training of the screw machine only needs to import the model related to moving components.

Figure 2 is the virtual prototype of screw machine of TBM:

\section{Dynamic Import of Model}

\subsection{Construction of Dynamic Model Base}

There are two kind ways of constructing the base of the dynamic model. They are geometric model base and model detail base. Geometric model base also can divide into fine model base, rough model base.

Fine model expresses all the detailed information of a three-dimensional model, and the model precision is higher, but it has the large amount of data. Rough model expresses main information of the three-dimensional model, and the model precision is moderate, it removes some parts such as chamfering, thread and so on, but it has smaller data. Each model has different model precision, from high model precision to lower. Because the same kind of model has the large number of models, several models of the different model precision are generated automatically by the program according to the different model precision.

The model precision, $\mathrm{u}$, is an index which it expresses the fine degree of the mode. It relates with the following factors: the distance $\mathrm{r} 1$ between the model and the viewpoint in the scene, the distance $\mathrm{r} 2$ between the model and operation point, the distance $r 3$ between the model and operation target; and the greater the $r 1, r 2$ and $r 3$ is, the smaller $u$ value is. The conclusion is the following:

$$
\mathrm{u}=1 / \mathrm{r} 1+1 / \mathrm{r} 2+1 / \mathrm{r} 3
$$

r1 ---- Distance between the model and the viewpoint in the scene, $\mathrm{mm}$

r2 ---- Distance between the model and operation point in the scene, $\mathrm{mm}$

r3 ---- Distance between the model and operation target in the scene, $\mathrm{mm}$

Because $u$ is the value between 0 and 1 . System generates several different precision models automatically by making $\mathrm{u}$ divide into a number of parts averagely between 0 and 1 according to some rules, gives models number and makes the address information of the models fill in the database. There is the corresponding relation between different model precision and the different model in virtual scene. This paper lists the relation in the database according to the importance of the details of the model for virtual training system. Table 1 descripts the relation 
between the model and model precision.

Figure 3 is the flow chart of model produced.

Model detail base is different form geometric model base; it bases on complete model whose model precision is one. According to model precision, it is constituted by the details which the remaining that the basic model compressed the rough model. So, it can avoid generating the same basic model in the geometric model base. The model in the model detail base is divided into several parts, its construction way is the same as geometric model base.

\subsection{Construction of the Post Information Database}

In the Virtual training, according to the modular training content, training system divides the training content according to the different mechanical equipment operating post, in order to achieve the good effect of training.

Because the different posts needs import the different models, the system establishes post database building the relation between the post and the model, the relation between the model and mode precision.

In addition, the database also defines the logic relation and the movement relation of parts in the post and so on.

\subsection{Process of Model Dynamic Import}

According to the different training posts, the system imports the different model; the trainees can choose the training post needed. According to the relation of the position of the models in the scene, the system calculates model precision in the scene currently, and produces the models or removes the needless details by matching this value with the model precision in the post database to find the geometric models or details, and builds the virtual scene.

At the same time according to the movement logical relation in the post database, the system produces operation panel automatically. Since then, the system can change u value in real-time. When the trainees operate in the virtual scene, and it will import the new models according to the new $u$ in the database. Figure 4 is the flow chart of dynamic model import.

\section{Example}

Above the geometric model base, model detail base and the post information database have been applied in the virtual training system of TBM, and it has been proved that the technology of dynamic import of model is feasibility in the virtual training system.

According to the different training post of TBM, the system imports dynamically when it is running, and replaces the models according to model precision in real-time.

Table 2 records the virtual scene of different training posts

There are many parts in TBM, and the structure of the single part is also very complex. So the system deals with the models according to model precision and some tools.

Figure 5 is the graph whose model precision is one. There are many details such as holes, corner and thread in the power box of the cutter system

The model precision of the model removed the corner is 0.75 , that removed holes and thread is 0.5 , that removed rib plate is 0.25 , and the model precision of the mode descripted by the picture is 0 .

\section{Conclusions}

The technology of dynamic import of model alleviates the pressure of the lower speed of the loading model and operation in the virtual training system, also provides the basis for the design of the training content. And it has applied in the virtual training system of TBM, also is proved that the technology is necessity and feasibility. With the virtual training technology developing in the manufacturing equipment industry, the technology also will be applied and developed further.

\section{References}

Du, B. J., Wang, L. P., \&Wu, E. Q. (2009). Real-time creating technology of virtual elements on virtual exhibition. Journal of Computer Applications, 29(12), 291-293.

Hu, X. G. (2008). Building of Dynamic and Three-Dimension Virtual Scene Based on VRML and Java. Science Mosaic, 3.

Ren, W. J., Zhang, Z. H., \& Dong, H. L. (2005). Application of Virtual Reality Technology in Simulation Training of Transportation and Storage of Oil and Gas. Journal of System Simulation, 17(6), 1418-1424. 
Yang, Y. B., Gong, Q. W., \& Cha, X. M. (2009). Virtual Substation Operator Training System Based on High Level Architecture. Journal of System Simulation, 21(18), 5760-5764.

Yang, Y. H., Su, M. D, \& Qiao, H.(2008). Complex Equipment Maintenance Training Simulation System (MTS). Journal of System Simulation, 20(11), 2885-2888.

Zhu, H. H., Xu, Q. W., \& Liao, S. M. (2007). Experimental study on thrust force during tunnel excavation with earth pressure balance shield machine. Rock and Soil Mechanics, 28(8), 1587-1594.

Table 1. Cross-reference between the model and model precision

\begin{tabular}{|l|l|l|l|l|l|}
\hline Model Precision u & 0 & 0.25 & 0.5 & 0.75 & 1 \\
\hline Description of model & $\begin{array}{l}\text { Picture or or } \\
\text { no details } \\
\text { information }\end{array}$ & $\begin{array}{l}\text { Removed } \\
\text { rib plate }\end{array}$ & $\begin{array}{l}\text { Removed } \\
\text { the thread }\end{array}$ & $\begin{array}{l}\text { Removed } \\
\text { corner }\end{array}$ & $\begin{array}{l}\text { all } \\
\text { information } \\
\text { of model }\end{array}$ \\
\hline
\end{tabular}

Table 2. Virtual scene of different training posts

\begin{tabular}{|l|l|}
\hline Training posts & Import model \\
\hline Operation of cutter & Cutter \\
\hline $\begin{array}{l}\text { Structure and principles of propulsion } \\
\text { system }\end{array}$ & Propulsion system \\
\hline Structure and principles of hinged device & Hinged device \\
\hline Structure and principles of screw machine & Screw machine \\
\hline Operation of forward & Cutter \\
\hline Operation of erector & Erector \\
\hline
\end{tabular}

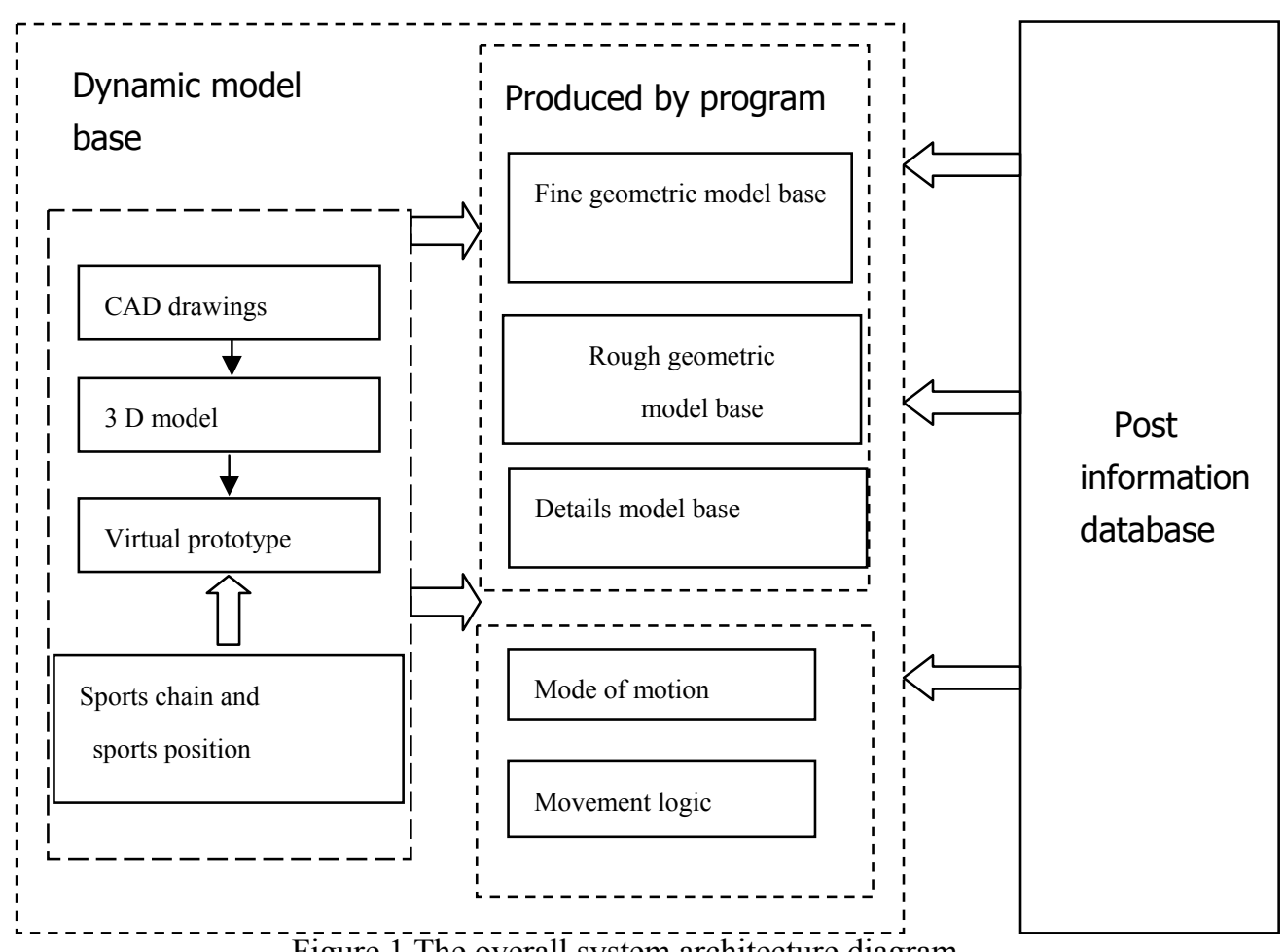

Figure 1.The overall system architecture diagram 


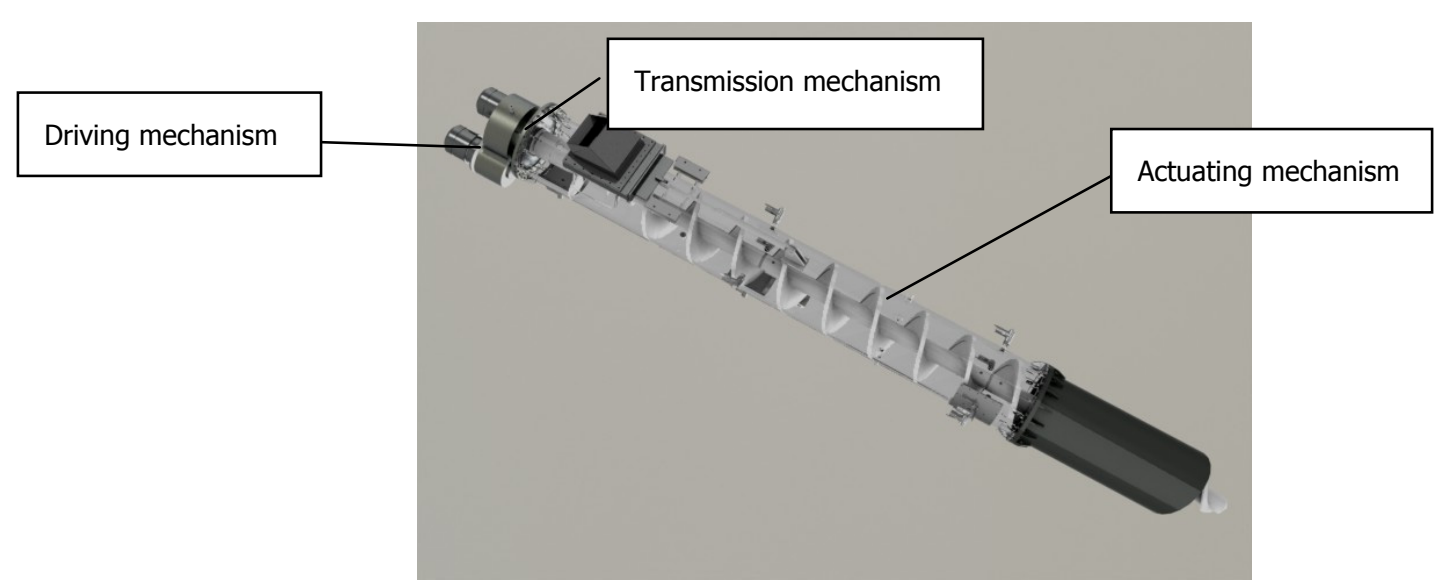

Figure 2. Virtual prototype of screw machine of TBM

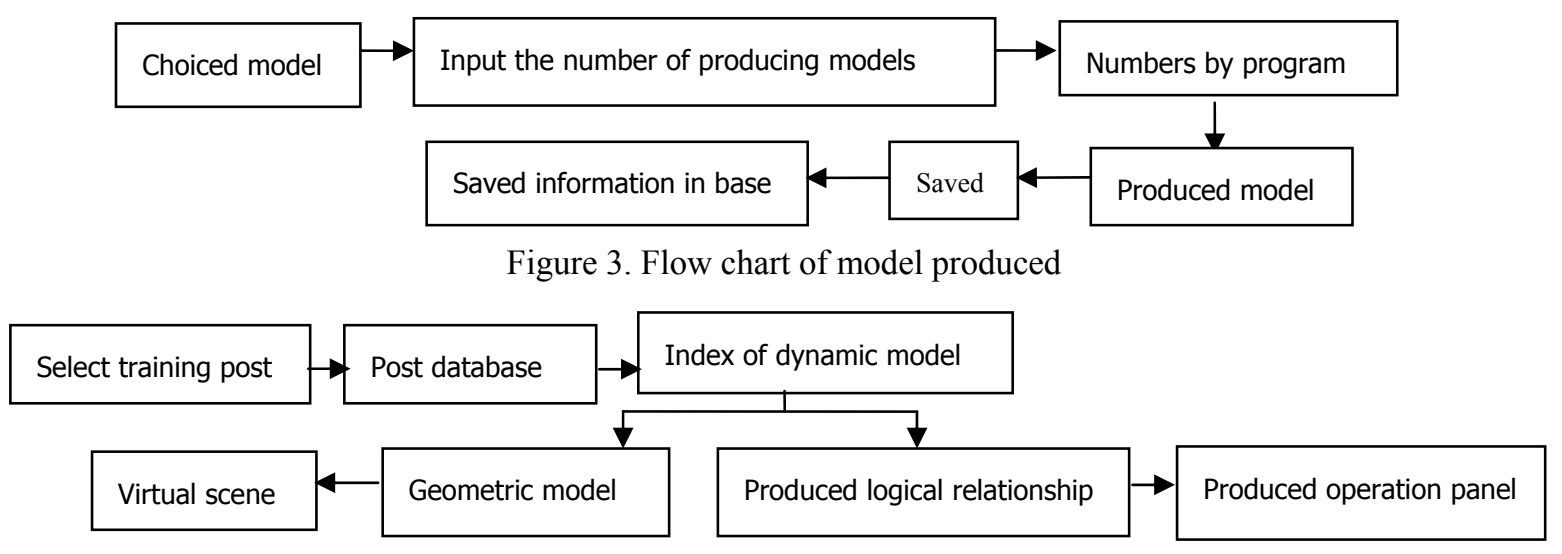

Figure 4. Flow chart of dynamic import of model

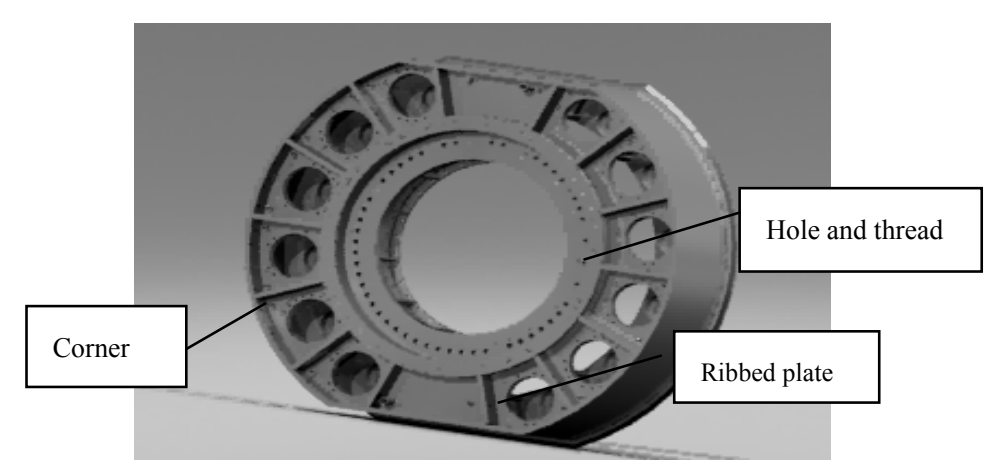

Figure 5. Model of power box 